\title{
Accounting
}

\section{Conceptual model for assessing the investment attractiveness of innovative projects of industrial enterprises}

\author{
Olena Petryk $^{a}$, Andriy Semenov ${ }^{b}$, Iryna Hnatenko ${ }^{*}$, Andrii Samiilenko ${ }^{a}$, Viktoriia Rubezhanska ${ }^{d}$ \\ and Oleksiy Patsarniuk ${ }^{\mathrm{a}}$
}

${ }^{a}$ Kyiv National Economic University named after Vadym Hetman, Ukraine

${ }^{b}$ Classic Private University, Ukraine

${ }^{c}$ Kyiv National University of Technologies and Design, Ukraine

${ }^{d}$ Luhansk Taras Shevchenko National University, Ukraine

\section{H R O N I C L E}

\section{Article history:}

Received: April 29, 2020

Received in revised format: July 302020

Accepted: August 10, 2020

Available online:

August 17, 2020

Keywords:

Innovation

Investment support

Economic and mathematical

modeling

Risk

Life cycle

\section{A B S T R A C T}

In a market economy, entrepreneurship requires large-scale innovations to maintain competitiveness and high rates of economic growth, and large investments are needed to implement innovations. However, in the process of their activities, investors face increased investment risk and therefore need reliable methods of investment evaluation and investment modeling of innovations in industrial enterprises. In this regard, the purpose of this study is to develop a conceptual model for assessing the investment attractiveness of innovative projects. The article builds a graphical model of investment in an innovative product at different stages of its life cycle. A conceptual structural and mathematical model for assessing the investment attractiveness of innovative projects of industrial enterprises has been developed, which reflected the stages of risk management, phases of the life cycle of the innovation project and the stages of the innovation process. The main idea of the proposed model is to manage investment in innovation based on the impact on the level of specific innovation risks.

\section{Introduction}

The integration of science and production in innovative industrial enterprises is one of the modern problems of the world economy. Experts are increasingly considering the innovation potential as a decisive factor in economic progress, while the "material" factors (size of the territory, population growth, climate, availability of minerals, etc.), which prevailed eralier, have receded into the background. It is innovation and related scientific and technological investment, rather than investment, that are increasingly becoming the most important factor in the competitiveness of enterprises (especially in the world market), and at the macro level - the main factor of intensive economic growth (Kuksa et al., 2019; Hnatenko et al., 2020). Simple production of a certain set of products using the existing set of technological processes does not allow a modern enterprise to last long in the market. To succeed in any time perspective, companies must innovate, which is of paramount importance forknowledgeintensive industries.

* Corresponding author. Tel.: +380953081789

E-mail address: rubezhiik@gmail.com (I. Hnatenko) 
Thus, large-scale innovation is needed to maintain competitiveness and high economic growth, and large investments are needed to innovate. In a market economy, investments are made mainly on a commercial basis with a focus on profits. However, when investing in innovations (innovation projects), the private investor faces increased investment risk and therefore needs reliable methods of investment evaluation and investment modeling of innovations in industrial enterprises (Goncharov et al., 2013; Hnatenko et al., 2020). In this regard, there is an urgent scientific task to improve methods of evaluation and modeling of investment activities of innovative industrial enterprises in order to maintain their competitiveness, increase the level of their intellectualization, increase innovation, integration of science and production. Only the development of new methods for assessing and modeling investments in technological and product innovations, and improvement of the existing ones will solve the problem of technological modernization of industry, increase production of competitive innovative products, the transition to an innovative type of economic growth.

\section{Literature review}

The scientific works of many scientists are devoted to the study of the peculiarities of the process of investing in innovative projects, risks of innovative activity, mechanisms of optimization of investment management in innovative products. Thus, Collins, Reutzel (2017) considered the role of top managers in the formation of innovation and investment activities of small and medium enterprises in India and found that investment in innovation is influenced by the perception of top managers about the attractiveness of innovation opportunities and their ability to assess investment value innovation. The results of research by Bantel, Jackson (1989) conducted in the banking sector showed that more innovative banks are managed by more experienced managers who have in-depth knowledge in functional areas of knowledge. McAdam, Moffett, Hazlett, Shevlin (2010) conducted an empirical study to develop and test the model of innovation in the activities of small and medium enterprises in the UK and assess their investment. Busru and Shanmugasundaram (2017) simulated and determined the direct relationship between R\&D expenditures and the growth and sustainability of economic performance in India. Bogliacino and Pianta (2010) examined the relationship between: the ability of technological developments to lead to successful innovation; the ability of innovations to stimulate significant profits from entrepreneurial activity; investing the profits in the further technological development of production at the enterprise and the level of its competitiveness. In the article Kostuchenko et al. (2016) cognitive modeling of investment attractiveness increase of innovative enterprises in the field of construction is carried out. Griebeler (2017) calculated economic and mathematical model of dependence of investments attraction level (including direct foreign investments) on corporate image of the organization. Miglioria et al. (2020) examines the relationship between family management of small and the propensity to invest in innovative development of small and medium enterprises in Italy. Bond, Harnoff, Van Reenen (2005) explored the importance of systematic investment of money in the fixed capital of the enterprise and its innovative development, and also the positive interrelation between volumes of investment in innovation and a level of competitiveness of the enterprises is established. In the article by Aseev et al. (2005) the optimal function of investment portfolio management of an innovative enterprise and its potential creditors is constructed.

Paying tribute to the above-mentioned scientific works, it should be noted the need for further research aimed at optimizing the assessment of investment attractiveness of innovative projects of industrial enterprises.

\section{Research results and discussion}

The review of experts' opinions on the issue of investment support of innovations allows us to highlight the following features of investment in innovative projects:

- constant growth of the share of innovative investments in the total investment of firms;

- specialized nature of innovative investments, due to the specifics of the created assets;

- relatively long investment cycle and payback period, which increases the risk of a temporary gap between costs and results;

- low liquidity of the project in its intermediate stages;

- uncertainty of a positive R\&D result;

- the difficulty of assessing the results obtained in the implementation of innovative projects, which is due to the presence of many criteria of technical, economic, social and political and strategic content;

- uniquely high level of innovation risks (compared to other types of investments);

- high level of potential profitability of innovative investments balances the high risk of losses;

- specificity of investment mechanisms used in financing scientific and technical innovations;

- dynamic management of innovative investments;

- making investment decisions in conditions of uncertainty.

Thus, five factors should be identified that cause increased risks of investment in innovation projects: uncertainty of future positive R\&D results, complexity of its accurate assessment, weak regulation and planning of R\&D, specialized nature of innovation investments (due to the specificity of investment assets used) and long payback period. 
O. Petryk et al. /Accounting 6 (2020)

Accordingly, the key parameters of investment in innovative projects are the project budget, its financial support (structure and volume of financial sources), the level of innovation risks, the internal rate of the projectrpofitability and the duration of the project cycle.

These parameters allow to create a descriptive graphical model of investment in an innovative product at different stages of its life cycle, presented in Fig. 1.

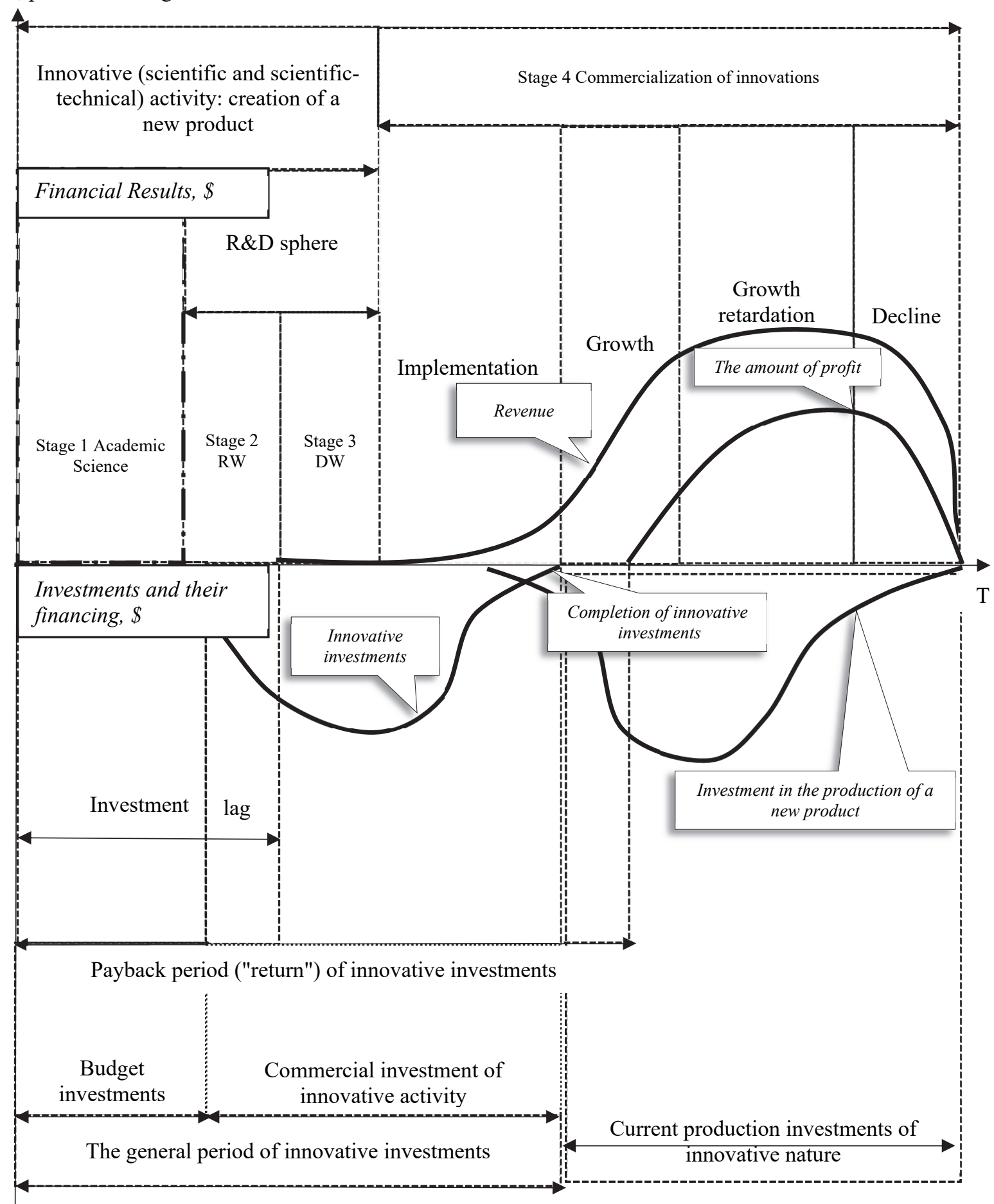

Fig. 1. Graphic model of the process of investing in an innovative product at different stages of its life cycle

It should be noted that the life cycle of an innovative product covers the period from the origin of a scientific idea to the moment of withdrawal from production of the product (which is the result of commercial development of this idea). That is, this concept is broader than the concepts of "innovation project life cycle" and "product life cycle". 
In the graphical model of the process of investing in innovation presented in Fig. 1, the emphasis is on the actual innovative investments aimed at developing a new, innovative product. Innovative investments are separated from "ordinary" production investments of non-innovative nature, carried out at the stage of commercialization of an innovative scientific and technical product. The specifics of the innovation process is that first (in the first phases of the life cycle) it is innovative investment that is carried out, while the subsequent income and profits that pay them off, are generated jointly by innovative and "regular" investments. In some cases, this may make it difficult to determine the return on innovation.

One of the advantages of the model presented in Fig. 1, is that the costs of development and subsequent production of a new product are shown in it in two ways. In the lower quadrant, they are shown directly - as investments, broken down into innovative and "ordinary". In the upper quadrant, they are shown indirectly and generalized - as the difference between income and profit, which represents the total cost of production, taking into account the discounted costs of R \& D (i.e. discounted innovation investment). Taking into account the depreciation of fixed assets (involved in both R\&D and production), the total cost of production will be less than the amount of investment.

Based on the above, the following conceptual structural-mathematical model for assessing the investment attractiveness of an innovative project is proposed, which is universal in nature and can be an element of any existing investment mechanism.

A key aspect of the model is innovation risk management. The model is based on the calculation of the project advantage index according to the formulas of qualitative profit and risk indicators, first proposed by Ansoff, who considers the advantage index as the most acceptable integrated indicator of the investment attractiveness degree of an innovative project.

The proposed conceptual structural-mathematical model assumes that the risk factor is a fundamental problem of investment support of innovative projects, and the final stage of analysis of innovation risks is the calculation of the individual discount rate for each project (based on the assessment of total and individual risks). The purpose of this model is to provide a comprehensive, systematic approach to investment decision-making in the field of innovative design. The model reflects the stages of risk management, phases of the life cycle of the innovation project and the stages of the innovation process. That is, the main idea of the presented model is investment management in innovation based on the impact on the level of specific innovation risks. The model is based on the fact that the level of innovation risks is not a given (exogenous) parameter, so by using different tools of project risk management it is possible to affect their size (minimize and optimize), thereby directly affecting the investment attractiveness of innovation projects and open a real opportunity for their financing. Scientifically based forecasting methods and financing mechanisms for innovative projects, contractual relations, organizational forms, etc. can provide additional information, establish guarantees for certain events and create the necessary incentives, thereby reducing transaction costs and influencing the amount of risk.

Thus, the proposed conceptual structural-mathematical modeling of investment attractiveness of innovative projects can be used at the two most difficult (due to uncertainty) stages of innovative design - stages of project selection and completion, opening space for more detailed modeling of investment management processes in innovative projects. However, the practical use of this model may be complicated by the quantification of project risks as far as, despite the objective nature of the risk, its main assessment indicator (namely, the level of risk) is subjective. This subjectivity, i.e. the inequality of assessment of this objective phenomenon, is due to the different level of completeness and reliability of the information base, the qualifications of investment managers, their experience in risk management, the assessment methods used and other factors. At the same time, the attitude to risk on the part of the management of enterprises determines the conditions under which decisions on R\&D should be made. In this regard, experts often point to the limited possibilities of mathematical modeling in the field of innovation management $(1-7)$ :

$$
\begin{aligned}
& H=\frac{(M t+M b)}{(C d+J) \times M r} \times N P V \times P t \times P p \times S \times Z \times 100 \%=f(N P V, P t, P p, S, Z)(\max ), \\
& N P V=-I_{0}+\sum_{t=1}^{T} \frac{F V_{t}}{(1+i)^{t}} \\
& i=r+w+\sum G_{I} \\
& P t=\left(1-R_{1}\right)+\cdots\left(1-R_{m}\right)=f\left(R_{1}, \ldots R_{m}\right)(\max ) \\
& P p=\left(1-R_{1}\right)+\cdots\left(1-R_{n}\right)=f\left(R_{1}, \ldots R_{n}\right)(\max ) \\
& Z=P_{I r} / P_{I}=P_{I r} /\left(\sum_{i=1}^{m} a_{i} x_{i}\right)^{\alpha}\left(\sum_{j=1}^{m} b_{j} y_{j}\right)^{\beta},
\end{aligned}
$$




$$
M r=\sum_{m=1}^{M} R_{m}+\sum_{n=1}^{N} R_{n}+\sum_{n=1}^{N} R_{I},
$$

where $H$ - project advantage index (as a percentage);

$M_{t}$ - indicator of the technical level of the project (in units);

$M_{b}$ - financial advantages of the project (in terms of liquidity) (in units);

$C_{d}$ - total costs for project development, including costs for applied research, capital investment, production capacity, additional staffing of the enterprise, etc. (in standard units);

$J$ - accumulation factor, which is expressed in the share use of existing specialized production facilities (in units);

$M_{r}$ - indicator of total risks for the respective project (in shares of the unit);

$N P V$ - total net discounted income for this project for the entire project cycle (in standard units);

$P_{t^{-}}$probability of technical success of the project (in shares of the unit);

$P_{p}$ - probability of commercial success of the project (in shares of the unit);

$S$ - strategic compliance of the designed scientific and technical product with other products, technologies and markets (in units);

$Z$ - the degree of use of the intellectual potential of the enterprise (in shares of the unit);

$F V_{t}$ - the amount of income in the year $t$ (in standard units);

$T$ - project planning horizon (number of years);

$i$ - individual discount rate, which reflects part of the risks of this project (in units);

$I_{0}$ - initial investment costs for the project (in standar units);

$r$ - real (adjusted for inflation) risk-free loan interest rate (real rate of return on loans, cleared of the inflation component);

$w$ - average inflation expectations for the settlement period. It is the inflation expectations regarding future financial flows that are relevant, not the actual inflation that has taken place;

$G_{I}$ - premium for a separate risk on the $I$-th risk factor. Only non-innovative systematic risks of a general nature, not reflected in the benefit index, are taken into account;

$R_{I}, \ldots R_{m}$ - technical risks of the project (in units);

$R_{I}, \ldots R_{n}$ - commercial risks of the project (in units);

$R_{I}, \ldots R_{I}$ - other risks of the project (in units);

$P_{I r}$ - realized intellectual potential of the enterprise (in standard units);

$P_{I}$ - available intellectual potential of the enterprise (in standard units).

Indicators $P_{I}$ i $P_{I r}$ are calculated by a formula based on the Cobb-Douglas model;

$x_{i}$ - the number of specialists of the $i$-th level $(i=1, \ldots n)$;

$a_{i}$ - "contribution" of specialists of the $i$-th level;

$y_{j}$ - the number of high-tech equipment of the $j$-th type, $(j=1, \ldots m)$;

$b_{j}-j$-type equipment performance;

$\alpha$ i $\beta$ - coefficients determined by the specifics of intellectual activity of specialists of the enterprise (as a rule, $\alpha+\beta=1$ ).

The proposed conceptual structural-mathematical model assumes that the risk factor is a fundamental problem of investment support of innovative projects, and the final stage of analysis of innovation risks is the calculation of the individual discount rate for each project (based on the assessment of total and individual risks). The purpose of this model is to provide a comprehensive, systematic approach to investment decision-making in the field of innovative design. The model reflects the stages of risk management, phases of the life cycle of the innovation project and the stages of the innovation process. That is, the main idea of the presented model is investment management in innovation based on the impact on the level of specific innovation risks. The model is based on the fact that the level of innovation risks is not a given (exogenous) parameter, so by using different tools of project risk management it is possible to affect their size (minimize and optimize), thereby directly affecting the investment attractiveness of innovation projects and open a real opportunity for their financing. Scientifically based forecasting methods and financing mechanisms for innovative projects, contractual relations, organizational forms, etc. can provide additional information, establish guarantees for certain events and create the necessary incentives, thereby reducing transaction costs and influencing the amount of risk.

Thus, the proposed conceptual structural-mathematical modeling of investment attractiveness of innovative projects can be used at the two most difficult (due to uncertainty) stages of innovative design - stages of project selection and completion, opening space for more detailed modeling of investment management processes in innovative projects. However, the practical use of this model may be complicated by the quantification of project risks as far as, despite the objective nature of the risk, its main assessment indicator (namely, the level of risk) is subjective. This subjectivity, i.e. the inequality of assessment of this objective phenomenon, is due to the different level of completeness and reliability of the information base, the qualifications of investment managers, their experience in risk management, the assessment methods used and other factors. At the same time, the attitude to risk on the part of the management of enterprises determines the conditions under which decisions on R\&D should be made. In this regard, experts often point to the limited possibilities of mathematical modeling in the field of innovation management. 


\section{Conclusions}

As a result of the research it is established that the development of new and improvement of existing methods of evaluation and modeling of investments in technological and product innovations will solve the problem of technological modernization of industry, increase production of competitive innovative products, transition toinnovative type of economic growth. At the same time, the most characteristic feature of investing in innovation is an unprecedented level of project risks. In this regard, the problem of investment risk management of an innovation project is the main in investing innovations. By using different tools to manage project risks can affect their size (minimize and optimize), and, thus, directly affect the degree of investment attractiveness of innovation projects financing. Scientifically based forecasting methods and financing mechanisms for innovative projects, contractual relations, etc. are able to provide additional information, establish guarantees for certain events and create the necessary incentives, thereby reducing transaction costs and influencing the amount of risk.

In order to solve the above problem, this study proposes a conceptual structural and mathematical model for assessing the investment attractiveness of innovative projects of industrial enterprises, which identified and formalized the relationship between the tools used to manage project risks and the degree of investment attractiveness of the project. This model is able due to its universal nature to be a fundamentally new element of any mechanism for commercial investment in innovation.

\section{References}

Collins, J. D., \& Reutzel, C. R. (2017). The role of top managers in determining investment in innovation: The case of small and medium-sized enterprises in India, International Small Business Journal, 35(5), 618-638.

Bantel, K. \& Jackson, S. (1989). Top Management and Innovations in Banking: Does the Composition of the Top Team Make a Difference? Strategic Management Journal, 10, 107-124.

Mcadam, R., Moffett, S., Hazlett, S. \& Shevlin, M. (2010). Developing a model of innovation implementation for UK SMEs: A path analysis and explanatory case analysis, International Small Business Journal, 28, 195-214.

Busru, S. A. \& Shanmugasundaram, G. (2017). Effects of Innovation Investment on Profitability and Moderating Role of Corporate Governance: Empirical Study of Indian Listed Firms, Indian Journal of Corporate Governance, $10(2), 97-117$.

Bogliacino, F. \& Pianta, M. (2010). Profits, R\&D and Innovation: a Model and a Test, IPTS Working Paper on Corporate R\&D and Innovation, 5, 1-21.

Bond, S., Harnoff, D. \& Van Reenen, J. (2005). Investment, R\&D and Financial Constraints in Britain and Germany, Annales D'Économie Et De Statistique, 79/80, 433-460.

Hnatenko, I., Orlova-Kurilova, O., Shtuler, I., Serzhanov, V. \& Rubezhanska, V. (2020). An Approach to Innovation Potential Evaluation as a Means of Enterprise Management Improving, International Journal of Supply and Operations Management, $7(1), 112-118$.

Kuksa, I., Shtuler, I., Orlova-Kurilova, O., Hnatenko, I. \& Rubezhanska, V. (2019). Innovation cluster as a mechanism for ensuring the enterprises interaction in the innovation sphere, Management Theory and Studies for Rural Business and Infrastructure Development, 41 (4), 487-500.

Samborskyi, O., Isaia, O., Hnatenko, I., Parkhomenko, O., Rubezhanska V. \& Yershova, O. (2020). Modeling of foreign direct investment impact on economic growth in a free market, Accounting, 6(5), 705-712.

Hnatenko, I., Kuksa, I., Naumenko, I., Baldyk, D. \& Rubezhanska, V. (2020). Infrastructure of innovation enterprise: features of formation and regulation in modern market conditions, Management Theory and Studies for Rural Business and Infrastructure Development, 42 (1), 97-104.

Goncharov, V.M., Zos-Kior, M. \& Rakhmetulina Z. (2013). The investment component of ukrainian agrarian enterprises' development in conditions of land reform, Actual Problems of Economics, 10(148), 118-125.

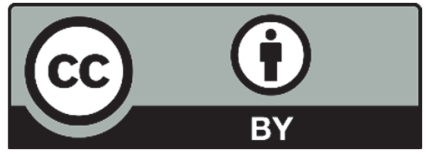

(C) 2020 by the authors; licensee Growing Science, Canada. This is an open access article distributed under the terms and conditions of the Creative Commons Attribution (CC-BY) license (http://creativecommons.org/licenses/by/4.0/). 